\title{
Investigations on Hydrotreating of Fischer Tropsch-Biowaxes for Generation of Bio-Products from Lignocellulosic Biomass
}

\author{
Harald Walter Schablitzky (Corresponding author) \\ OMV Refining \& Marketing, Department for Fuels, Innovation \& Quality, Austria \\ Tel: 43-1-40440-42532 E-mail: harald.schablitzky@omv.com \\ Josef Lichtscheidl \\ OMV Refining \& Marketing, Department for New Technology, Austria \\ Tel: 43-1-40440-42248Ｅ-mail: josef.lichtscheidl@omv.com \\ Reinhard Rauch \\ Bioenergy 2020, Inffeldgasse 21b, 8010 Graz, Austria \\ Tel: 43-1-58801-15954 E-mail: rrauch@mail.zserv.tuwien.ac.at \\ Hermann Hofbauer \\ Vienna University of Technology, Institute for Chemical Engineering, Austria \\ Tel: 43-1-58801-15970 E-mail: hhofba@mail.zserv.tuwien.ac.at
}

\author{
Received: January 25, 2012 Accepted: February 23, $2012 \quad$ Published: April 1, 2012 \\ doi:10.5539/mas.v6n4p28 \\ URL: http://dx.doi.org/10.5539/mas.v6n4p28
}

The research is funded by Future Energy Fund Austria (FFG)

\begin{abstract}
The present study describes the application of Fischer Tropsch biowaxes as a feedstock in a pilot-scale hydroprocessing unit at operating conditions very similar to industrial size hydrotreating plants of traditional refineries. The project focus on a future coprocessing of biowax/gasoil blends due to produce bio-products derived from lignocellulosic biomass: crack gases, naphtha, kerosene, diesel and a residual product. Hydro-processing plants operating at mild cracking conditions support the production of high amounts in middle distillates at reduced coke formation. Premium bio-diesel and bio-kerosene with excellent cold flow properties are the main objective of the investigations. Various test runs with different hydrotreating catalysts have been conducted due to determine the influence of waxy feedstock on catalyst behavior and product distribution. Depending on the catalyst selected, the fixed bed reactor streamed by hydrogen operates under specified cracking condition defined by the following parameters: reactor temperature, hydrogen pressure and weight hourly space velocity (WHSV). Test runs with selected catalysts - isodewaxing (IDW), hydro-desulphurization (HDS) and the catalytic deparaffination (CDP) catalyst - have been executed at constant process conditions in order to compare the product spectrum and properties of product groups. Highest amounts of bio-diesel and bio-kerosene with excellent cold flow properties can be obtained with the IDW catalyst. This NiW- based catalyst with special additives generates cleaved and reshaped molecular fragments via skeletal isomerisation increasing the isoparaffin content of naphtha and middle distillates. Further investigations with this catalyst type have been executed due to determine the catalyst aging effect in a separate long term test run. The loss of cracking severity during operation of the catalyst can be observed by a steady decline in conversion. Unsaturated hydrocarbons such as olefins and diolefines in the bio-feedstock support the formation of a coke layer on the catalyst surface resulting in reinforced deactivation. As the consequence naphtha and finally the crack gases and the kerosene fraction are shifted to higher molecular fragments increasing the diesel and residue yield. Physicochemical properties of the product groups obtained during the test run vary and especially the cold flow
\end{abstract}


properties from the diesel and kerosene fraction degrade significant. Balancing the conversion decline of the catalyst in operation can be realized by increasing the reactor temperature and the hydrogen pressure, but the effect is time limited.

Keywords: BTL, Hydrorefining, Hydroprocessing, Coprocessing, Premium Biodiesel

\section{Introduction}

The conversion process route with the key technology gasification, FT- synthesis and hydrotreating offers a high potential for creation of high paraffinic products. Feeding the gasification unit with lignocellulosic biomass instead of fossil goods as executed in the CHP- plant Güssing (Austria) creates depending on operating conditions of FT synthesis the $2^{\text {nd }}$ gen. bio-products: gases, naphtha, diesel and the main product waxes.

Hydrotreating plants installed at traditional refineries operate at mild cracking conditions for upgrading of crude oil components (gasoils) to the main products diesel and kerosene. Co- hydroprocessing of FT-biowaxes with fossil gasoil requires only adaption of already existing refinery infrastructure and avoids any contamination of diesel or kerosene product with oxygenates. The final product consists again of pure hydrocarbons enriched with paraffins increasing cetane number of diesel fuel as well as reducing the smoke point of kerosene fraction. Proper isodewaxing catalysts generate even second generation bio-diesel fuels with quality properties such as of a high cetane number combined with extraordinary deep cold flow properties. Naphtha and crack gas fractions with high amounts of linear paraffins offer an ideal feedstock for steam cracking to olefinic products. Steam cracking as a thermal cracking step is performed in tube ovens to generate olefinic products for various applications. Smaller olefins such as ethylene and propylene are used as monomers for polymerization to thermoplastics. Amounts of isobutene within the product portfolio react with ethanol to the octane number improver ethyl tertiare butyl ether (ETBE). The high content of diolefins such as butadiene is utilized to produce synthetic rubber for e.g. tire production. Therefore the substitution of fossil gasoil, by renewable compounds such as FT-biowaxes secures the economical operation of existing refinery plants with a high efficiency and reduces fossil $\mathrm{CO}_{2}$ emissions. FT-biowaxes consist compared to bio oils (vegetable oil, animal oils and fats) of low amounts in oxygenates resulting in generation of negligible amounts of by-products that reduce efficiency.

Oxygenates in the biodiesel fuel support the growth of micro organism and damage the fuel transport components of engines due to missing adapted equipment in standard vehicles. Paraffinic structures in FT-biowaxes consist of negligible amounts of oxygenates and show basically a high ability for cleavage of C-C bonds even under mild cracking conditions. Such components offer therefore an amazing potential for creation of designed products with special properties, especially in the diesel boiling range. Second generation bio-fuels originated from lignocellulosic biomass reach currently highest accounting rates concerning greenhouse gas emissions.

Olschar et al. (2007) studied hydrocracking of FT- waxes based on coal and a crude oil derived n- paraffinic wax fraction to diesel with commercially available base metal catalysts at various process parameters under mild conditions. Calemma et al. (2000-2010) investigated the hydrocracking behavior of a platinum on amorphous silica- alumina catalyst and confirmed the high potential of wax hydroprocessing to high quality fuels in the diesel boiling range. Mikulec et al. (2010) researched the reaction pathways at hydroprocessing of triglycerides with NiMo and NiW based hydro-desulphurization catalysts at mild hydrocracking conditions. They converted blends of triglycerides with atmospheric gas oil to second generation biodiesel and found out that selectivity to hydrodeoxygenation/ hydrodecarboxylation rises with increasing reactor temperature.

\section{Concept and Methodology}

The catalytic cracking process is realized by diffusion of FT-biowax molecules into the catalyst pore structure where the chemical reactions proceed on acid sites (Brønsted and Lewis sites) of zeolite structures. Additionally the crack products obtained from aluminosilicate catalyst matrix are released. Hydrogen saturates molecular fragments and reduces primary formation of olefins and aromatics. Schablitzky et al. (2011) investigated the ability of bifunctional catalysts for cracking and hydrogenation of paraffinic feedstocks due to obtain second generation biofuels in the diesel boiling range. The experiments with FT-biowax as the feedstock were conducted in a pilot-scale hydroprocessing unit.

In a fixed bed reactor tube two different catalyst layers (Catalyst A \& B) are filled and separated by a spacer material (ceramic balls). During operation the reactor is streamed with hydrogen under pressure in order to saturate molecular fragments and to reduce the formation of a coke layer around the catalyst particle surface. Complete liquefied biowax at $130^{\circ} \mathrm{C}$ is filled continuously into the reactor and contacts the hot catalyst particles. The first catalyst bed (Catalyst A) performs the hydrogenation of impurities (compounds with heteroatom's) in 
waxy feed and is diluted by Silica Carbide to avoid overcracking in the pretreating step. This pretreatment ensures protection of the second processing catalyst realizing mild hydrocracking (hydrotreating) combined with isomerisation of long hydrocarbon molecules into smaller and branched fragments.

Different processing catalysts (Catalyst B) have been examined under process conditions very similar to industrial size plants in refineries. The corresponding process parameters for each catalyst B - reactor temperature, weight hourly space velocity (WHSV) and hydrogen pressure - are illustrated in Table 1.

All experiments were conducted as continuous test runs monitoring temperatures and pressures in the reactor chamber of the pilot plant online. For comparision of conversion rate and product spectrum as well as characteristics of products obtained the isodewaxing (IDW), hydrodesulphuration (HDS) and catalytic deparaffination catalysts (CDP) have been selected. These catalysts operate in crude oil refineries to produce treated middle distillates from atmospheric distillation (gasoil's) as well as the top side bulk from vacuum distillation (vacuum gasoil).

FT-biowaxes are the main product of FT-synthesis originated from product gas that is generated by gasification of woody biomass. The composition of Fischer Tropsch biowaxes from CHP-biomass plant in Guessing, Austria applied for hydrotreating is shown in Figure 2. Beside the main component n-paraffins, biowaxes consist of appreciable amounts of unsaturated hydrocarbons (olefins) as well as isoparaffins and negligible amounts of oxygenates (alcohols). The carbon number spectrum shows a hydrocarbon chain length profile that can be expressed by the Anderson Schulz Flory- distribution curve with the chain growth probability factor $\alpha \sim 0.9$. Several characteristic properties of the FT- biowaxes are presented in Table 2.

The gaseous fraction of the reactor releases the product vessel, expands via pressure reducing valve to enable sampling of liquid product. Latter is separated by distillation according defined boiling ranges and analysed via gas chromatography (GC). Furthermore the liquid crude is separated into naphtha, kerosene, diesel and a residue by distillation according defined boiling ranges (Figure 3). The gas fraction ( $\mathrm{C} 1$ to $\mathrm{C} 4$ hydrocarbons) consists mainly of saturated paraffins such as $\mathrm{i} / \mathrm{n}$-alkanes, and is contaminated with excess hydrogen from feeding the reactor. The yield of the byproduct water is negligible due to the low oxygen content of FT-biowaxes. Coke is generated on the catalyst particle surface caused by creation of olefins and diolefins during the cracking process. The conversion of the hydrotreating process can be defined by the following expression:

\section{Results and Discussion}

$$
\text { Conversion }=\frac{m_{\text {Gas }}+m_{\text {Naphtha }}+m_{\text {Diesel }}}{m_{\text {Feed }}}
$$

The first experimental program was conducted with pure FT- biowax as well as blends with 5\% Vol gasoil and shows significant differences in conversion rate as well as product characteristics between the catalysts selected. In accordance with the catalyst manufacturer cracking conditions have been applied very close to the optimized operation points of industrial size hydrotreating plants. Highest conversion rates can be obtained according Figure 4 with the catalytic deparaffination catalyst (CDP). This catalyst type operates at a higher cracking severity (pressure: $8 \mathrm{MPa}$ ) and has therefore a higher hydrogen consumption for processing, shifting the product spectrum to an increased naphtha yield and a lower residue amount. Concerning the product yields counting to the conversion, a complete inconsistent distribution can be observed. Highest amounts of middle distillates can be achieved with the isodewaxing catalyst (IDW), followed by the CDP and the hydro-desulphurisation (HDS) catalyst. With the IDW catalyst the kerosene amount of total diesel fraction contains up to $43 \%$. The kerosene fraction of both other catalysts lies below $7.1 \% \mathrm{wt}$, compared to the $12.7 \% \mathrm{wt}$ with the IDW catalyst. Additionally the naphtha yield reaches highest values with the CDP catalyst and lowest values with the IDW whereas highest amounts of crack gases can be obtained with the HDS catalyst. The residue obtained with the IDW and the HDS catalyst is nearly equal with approximately $20 \% \mathrm{wt}$ and therefore higher compared to the CDP catalyst with only $12 \%$ wt. Synthetic diesel fuels from hydroprocessing consist according Schablitzky et al. (2011) mainly of isoparaffins, n-paraffins and low amounts of aromatics $(<2.6 \% \mathrm{wt})$. Other compounds such as alkenes or oxygenates cannot be detected or lie under detection limit of 2 dimensional gas chromatography (2d GC) analysis. Therefore the composition of the diesel fuel analysed by $1 \mathrm{~d}$ GC can be simply divided into the n-paraffin graph and the sum graph indicating isoparaffins with a low aromatic amount. The diesel profile curves presented in Figure 5 differ significantly between the three investigated catalyst types. The IDW and the HDS catalyst show a steady diesel spectrum of mainly isoparaffins over a wider $\mathrm{C}$ - number range. The corresponding n-paraffin distribution of HPFT-diesel created by IDW catalyst indicates a progressive increase of fractions till to the peak at C17. Highest cracking severity of all catalysts investigated has the CDP catalyst, visible in significant peaks at lower $\mathrm{C}$ - numbers in diesel profile. Basically the n-paraffin and isoparaffin distribution have a similar 
curve trend that differs in amounts and a shift in the $\mathrm{C}$ - number range. The peak of the isoparaffins lies at $\mathrm{C} 11$ whereas the peak for the $\mathrm{n}$-paraffins is shifted to the right side and recognizable at $\mathrm{C} 12$.

Furthermore the physicochemical properties for comparision of FT-diesel originated from FT-synthesis with HPFT-diesel fuels created by hydrotreating of FT- biowaxes are collected in Table 3 . Higher amounts of smaller hydrocarbon fragments in the diesel boiling range improve the cold flow properties as pointed out with the CDP catalyst. On the other hand isomerisation of n-paraffinic feedstock has an immense influence in cold flow properties indicated by the analysis parameters such as cold filter plugging point (CFPP) and cloud point (CP). Best results of cold flow properties at high cetane number can be achieved with the isodewaxing catalyst. Compared to the FT- diesel with an identical boiling range, HPFT diesel fuels are characterized by better cold flow properties at marginal lower cetane numbers due to a different $\mathrm{i} / \mathrm{n}$ - paraffin ratio.

Further investigations according long term processing stability have been executed with the isodewaxing catalyst (IDW) at constant WHSV $=0.67 \mathrm{~h}^{-1}$ to point out the tendency in product yields and conversion over runtime (Figure 6). To avoide desulphurization of the pretreating catalyst (Catalyst A) resulting in poisioning of the processing catalyst (Catalyst B) the FT-biowax feedstock is blended with $5 \%$ Vol of heavy gasoil (HGO) from crude oil distillation. As the conclusion of the results obtained conversion decreases linear by $3 \%$ in 50 hours due to aging behaviour of the catalyst. Capturing of catalyst poisons such as metals and the continuous formation of coke patches on the catalyst surface, caused by olefinic components in feedstock, result in deactivation of the catalysts. For balancing the proceeding conversion decline an increase of the reactor temperature by $5{ }^{\circ} \mathrm{C}$ reactivates the catalyst temporary, but results in a higher drop of conversion within a shorter period afterwards. A further raise of the processing temperature by $5^{\circ} \mathrm{C}$ doesn't improve the conversion anymore. As the consequence further balancing of activity loss can only be realized by increasing the partial hydrogen pressure in the reaction chamber. The corresponding yields depending on process conditions and runtime are pointed out in Figure 7. Within 64 hours in operation the naphtha yield decreases more than the diesel yield increases at a nearly constant kerosene fraction. As the conclusion cracking severity loses continuously with proceeding runtime shifting the product spectrum to longer hydrocarbons in the diesel boiling range and to the residue fraction. Forcing the temperature by $5{ }^{\circ} \mathrm{C}$ boosts the cracking again, resulting in similar product yields compared to the processing at the beginning. As mentioned before product yields vary much faster than at previous reactor conditions causing in a loss of naphtha as well as kerosene fraction combined with a significant increase of diesel and residue. A further raise of reactor temperature by $5{ }^{\circ} \mathrm{C}$ results basically in a lower naphtha yield at a constant kerosene fraction and a higher residue. Finally increasing the hydrogen pressure in the reaction chamber leads to an extension of the naphtha and kerosene fraction but reduces the diesel and residue yield. An overview of the product yields indicated as a bar diagram (Figure 7) quantifies the dimension of the changes in product portfolio depending on processing conditions and runtime. Additionally the tendency in the $\mathrm{C}$ - number distribution curves of the diesel fuel $\left(\mathrm{T}_{\mathrm{b}}=175-380{ }^{\circ} \mathrm{C}\right)$ analysed via $1 \mathrm{~d}$ GC encodes impact of catalyst aging behaviour over runtime at constant pressure conditions. The nearly monomodal isoparaffin - aromatics sum curves illustrate a peak at $\mathrm{C} 11$ and $\mathrm{C} 12$ that declines according the runtime. Furthermore the fraction amounts of isoparaffins decrease within the $\mathrm{C}$ - number range lower than $\mathrm{C} 16$ andbetween $\mathrm{C} 17$ and $\mathrm{C} 22$ significantly. This shift of the $\mathrm{C}$-number distribution to the right side as well as the loss in isomerisation and branching grade are esponsible for the differences in fuel characteristics as illustrated in Table 4. The excellent cold flow properties (CP, CFPP) of HPFT-diesel declines from $-50{ }^{\circ} \mathrm{C}$ to $-31,2{ }^{\circ} \mathrm{C}$ as the consequence of the catalyst aging effect finally resulting in reduction of cracking efficiency and less isomerisation of linear paraffinic molecular fragments. A similar tendency can be mentioned at the kerosene fraction $\left(\mathrm{T}_{\mathrm{b}}=175-225^{\circ} \mathrm{C}\right)$ ranging from $\mathrm{C} 10$ to $\mathrm{C} 14$ with excellent freezing point values down to $-80^{\circ} \mathrm{C}$. Due to the loss in catalyst activity the freezing point (FP) decreases not so dramatically compared to the diesel fraction. The sum curves of isoparaffins and aromatics can be expressed by a Gaussian distribution curve. Figure 9 shows a recognizable decline of the isoparaffin peak and an increase of the n- paraffin distribution curve depending on runtime.

Finally the physicochemical properties of the HPFT- kerosene depending on runtime and reactor temperature are collected in Table 5. As the result $\mathrm{i} / \mathrm{n}$-paraffin ratio combined with the cracking/isomerisation, severity declines over runtime that is responsible for a slight reduction of the extreme deep freezing point. The changes in chemical structure have a negligible impact on density and viscosity of kerosene fraction.

\section{Conclusion and Outlook}

Fischer Tropsch biowaxes from CHP- plant in Güssing (Austria) and blends with 5\% Vol of fossil gasoil were converted to bio-products in a hydroprocessing pilot plant at OMV. A pretreating catalyst filled in a fixed bed reactor protects the processing catalyst via hydrogenation of impurities in the feedstock. Latter performs conversion of the waxy feed via hydrotreating - mild hydrocracking combined with isomerisation of molecular 
fragments obtained. The investigations have been conducted with selected processing catalysts such as isodewaxing (IDW), hydro-desulphurisation (HDS) and catalytic deparaffination (CDP) focusing on a future coprocessing with fossil feedstock. All the continuous test runs were performed without essential modifications to the pilot plant at operating conditions very similar to industrial size hydrotreating plants. Hydroconversion of liquefied feedstock (FT-biowax) and fossil gasoil generates the products - gases, naphtha, diesel including the kerosene amount and a residue. The conversion - sum of hydrocarbon gases, naphtha and the total diesel fraction based on the feedstock - diversify by selection of processing catalyst type and shifting of process parameters (temperature, pressure and WHSV). The first test program with mainly FT-biowax as feedstock and selected catalysts operating at typical process conditions in refineries indicate amazing differences in product portfolio, conversion rate and diesel properties. Highest cracking severity could be observed with the CDP catalyst generating also highest naphtha fraction. The HDS catalyst generates lowest amounts of diesel fraction compared to the other catalysts tested and has the lowest conversion rate. Best results concerning diesel and kerosene yield could be reached with the isodewaxing (IDW) catalyst creating best fuel characteristics from all investigated catalysts. The high kerosene amount and the considerable content of isoparaffins in the HPFT-diesel are responsible for excellent cold flow properties (CP, CFPP- as low as $\left.-60{ }^{\circ} \mathrm{C}\right)$. Furthermore the bio-kerosene fraction $(\mathrm{C} 10-\mathrm{C} 14)$ is characterized by a very low freezing point of $-80{ }^{\circ} \mathrm{C}$, even capable as a blending component for Jet-fuels utilized in arctic regions. To investigate the cracking stability behaviour of this IDW catalyst a long term study in an experimental scale has been executed. According the results obtained conversion declines by $3 \%$ over a duration of 50 hours in operation. An increase of the reactor temperature by $5{ }^{\circ} \mathrm{C}$ boosts the secondary cracking reactions again, resulting in similar product yields compared to the processing at the beginning. Product yields vary much faster than at previous conditions in the reactor chamber causing in loss of naphtha and kerosene fraction and in a significant increase of diesel and residue. A further raise of the reaction temperature by $5{ }^{\circ} \mathrm{C}$ results basically in a lower naphtha yield at a constant kerosene fraction and a higher residue. Finally the increase of the partial hydrogen pressure in the reaction chamber effects in an extension of the naphtha and kerosene fraction as well as a reduction of the diesel and the residue. The FT-biowax contains high amounts of unsaturated hydrocarbons (alkenes), which support the formation of a coke layer around the catalyst particle surface causing in partial deactivation. In addition the sensibility of catalyst concerning low amounts of steam generated by hydrogenation of oxygenates from FT-biowaxes may influence catalyst activity and reaction behaviour over runtime. HPFT-diesel products generated by hydroconversion of FT- biowaxes differ from FT- diesel by slightly lower cetane numbers but remarkably better cold flow properties and consist of mainly paraffinic hydrocarbons. Further investigations are essential to confirm the potential of the high paraffinic HPFT-naphtha and crack gases as a feedstock for thermal steam cracking due to produce petrochemicals.

\section{References}

Adjaye, J. D., \& Bakhshi, N. N. (1995). Catalytic Conversion of a Biomass- derived Oil to Fuels and Chemicals I: Model compound studies and reaction pathways. Biomass and Bioenergy, 8(3), 131-149. http://dx.doi.org/10.1016/0961-9534(95)00018-3

Calemma, V., Peratello, S., \& Perego, C. (2000). Hydroisomerization and hydrocracking of long chain n-alkanes on $\mathrm{Pt} /$ amorphous $\mathrm{SiO}_{2}-\mathrm{Al}_{2} \mathrm{O}_{3}$ catalyst. Applied Catalysts A: General, 190(1-2), 207-218. http://dx.doi.org/10.1016/S0926-860X(99)00292-6

Calemma, V., Correra, S., Perego, C., Pollesel, P., \& Pellegrini, L. (2005). Hydroconversion of Fischer-Tropsch waxes: Assessment of the operating conditions effect by factorial design experiments. Catalysis Today, 106, 282-287. http://dx.doi.org/10.1016/j.cattod.2005.07.185

Calemma, V., Gambaro, Ch., Parker, W. Jr., Carbone, R., Giardino, R., \& Scorletti, P. (2009). Middle distillates from hydrocracking of FT waxes Composition, characteristics and emission properties. Catalysis Today, 149(1-2), 40-46. http://dx.doi.org/10.1016/j.cattod.2009.03.018

Dupain, X., Krul, R. A., Makkee, M., \& Moulijn, J. A. (2005). Are Fischer Tropsch waxes good feedstocks for fluid catalytic cracking units? Catalyst Today, 106, 288-292. http://dx.doi.org/10.1016/j.cattod.2005.07.148

Guzman, A., Torres, J. E., Prada, L. P., \& Nuñez, M. L. (2009). Hydroprocessing of crude palm oil at pilot scale. Catalysis Today, 156(1-2), 38-43. http://dx.doi.org/10.1016/j.cattod.2009.11.015

Huber, G. W., \& Corma, A. (2007). Synergies between Bio- and Oil Refineries for the Production of Fuels from Biomass. Angew Chem Int Ed Engl, 46(38), 7184-201.

Kubičková, I., Snåre, M., Eränen, K., Mäki-Arvela, P., \& Yu, M. D. (2005). Hydrocarbons for diesel fuel via 
decarboxylation of vegetable oils. Catalysis Today, 106, 197-200. http://dx.doi.org/10.1016/j.cattod.2005.07.188

Leckel, D., \& Ehumbu, M. L. (2006). Diesel Selective Hydrocracking of Iron- based Fischer Tropsch Waxes, Fraction C15- C45, Using a $\mathrm{MoO}_{3}$ - Modified Noble Metal Catalyst. Energy \& Fuels, 6, 2330-2336.

Mapiour, M., Sundaramurthy, V., Dalai, A. K., \& Adjaye, J. (2010). Effects of the operating variables on hydrotreating on heavy gas oil: Experimental, modeling and kinetic studies. Fuel, 89(9), 2536-2543. http://dx.doi.org/10.1016/j.fuel.2010.02.024

Mikulec, J., Cvengroš, J., Joríková, L., Banič, M., \& Kleinová, A. (2010) Second generation diesel fuel from rebewable sources. Journal of Clean Production, 18(9), 917-926. http://dx.doi.org/10.1016/j.jclepro.2010.01.018

Olschar, M., Endisch, M., Dimmig, Th., \& Kuchling, Th. (2007). Investigation of Catalytic Hydrocracking of Fischer Tropsch Wax for the Production of Transportation Fuels. OIL GAS European Magazine, 33(4), 187-193.

Schablitzky, H. W., Lichtscheidl, J., Hutter, K., Hafner, Ch., Rauch, R., \& Hofbauer, H. (2011). Hydroprocessing of Fischer Tropsch biowaxes to second generation biofuels. Biomass Conversion and Biorefinery, 1(1), 29-37. http://dx.doi.org/10.1007/s13399-010-0003-x

\section{Notation}

CHP- plant Combined heat and power plant

CFPP Cold filter plugging point, ${ }^{\circ} \mathrm{C}$

CP Cloud point, ${ }^{\circ} \mathrm{C}$

HFRR High frequency reciprocating rig

FT Fischer Tropsch

HPFT Hydroprocessing FT

WHSV Weight hourly space velocity, $\mathrm{h}^{-1}$

DCN Derived Cetane number

HGO Heavy Gasoil

1(2)d GC 1(2) dimensional Gas chromatograph

$\mathrm{m}_{\text {Gas }} \quad$ Mass gas fraction, $\mathrm{kg}$

$\mathrm{m}_{\text {Naphtha }} \quad$ Mass naphtha fraction, $\mathrm{kg}$

$\mathrm{m}_{\text {Diesel }} \quad$ Mass diesel fraction, $\mathrm{kg}$

$\mathrm{m}_{\text {Feed }} \quad$ Mass feed, $\mathrm{kg}$

Table 1. Operating conditions (Catalyst B)

\begin{tabular}{|l|l|l|l|l|}
\hline \multicolumn{1}{|c|}{ Parameter } & \multicolumn{1}{c|}{ Unit } & \multicolumn{1}{c|}{ IDW } & \multicolumn{1}{c|}{ HDS } & \multicolumn{1}{c|}{ CDP } \\
\hline Feed & & \multicolumn{3}{c|}{ FT-Biowax \& Gasoil } \\
\hline Temperature & ${ }^{\circ} \mathrm{C}$ & $385(395)$ & 375 & 360 \\
\hline WHSV & $\mathrm{h}^{-1}$ & 0.67 & 0.87 & 0.46 \\
\hline Pressure & $\mathrm{MPa}$ & $6-8$ & 6 & 8 \\
\hline
\end{tabular}

Table 2. Properties of FT- Biowax (Guessing)

\begin{tabular}{|l|l|}
\hline \multicolumn{1}{|c|}{ Property } & \multicolumn{1}{c|}{ Size } \\
\hline Melting Range & $38-110^{\circ} \mathrm{C}$ \\
\hline Amount $\left(\mathrm{T}_{\mathrm{b}}>300^{\circ} \mathrm{C}\right)$ & $62 \% \mathrm{wt}$ \\
\hline$\rho_{130^{\circ} \mathrm{C}}$ & $0.742 \mathrm{~kg} / \mathrm{dm}^{3}$ \\
\hline$v_{130^{\circ} \mathrm{C}}$ & $6.62 \mathrm{~mm}^{2} / \mathrm{s}$ \\
\hline $\mathrm{C} / \mathrm{H} / \mathrm{O}$ & $85 / 14.7 / 0.3 \% \mathrm{wt}$ \\
\hline
\end{tabular}


Table 3. Physicochemical Properties of Synthetic Diesel- Fuels

\begin{tabular}{|c|c|c|c|c|c|}
\hline Parameter & Unit & $\begin{array}{c}\text { FT- } \\
\text { Diesel }\end{array}$ & \multicolumn{3}{|c|}{ HPFT- Diesel } \\
\hline Catalyst Type & & - & IDW & HDS & CDP \\
\hline Temp./ WHSV / Press. & ${ }^{\circ} \mathrm{C} / \mathrm{h}^{-1} / \mathrm{MPa}$ & - & $390 / 0.67 / 6$ & $375 / 0.87 / 6$ & $360 / 0.46 / 8$ \\
\hline Feed & & Syngas & FT- Biowax & \multicolumn{2}{|c|}{ FT- Biowax $/ \mathrm{HGO}=95 / 5$} \\
\hline Boiling Range & ${ }^{\circ} \mathrm{C}$ & $180-320$ & \multicolumn{3}{|c|}{$180-320$} \\
\hline C-Number Range & - & $\mathrm{C} 7-\mathrm{C} 21$ & \multicolumn{3}{|c|}{$\mathrm{C} 10-\mathrm{C} 21$} \\
\hline i/ n- Paraffins & $\%$ & $3.3 / 67.4$ & $92.8 / 4.6$ & $66.9 / 30.6$ & $58.3 / 39.0$ \\
\hline Alkenes/Aromatics & $\%$ & $19.6 / 3.5$ & $-/ 2.6$ & $-/ 2.5$ & $-/ 2.7$ \\
\hline Oxygenates/ Water & $\% / \mathrm{ppm}$ & $6.2 / 482$ & - & - & - \\
\hline$\rho_{15^{\circ} \mathrm{C}}$ & $\mathrm{kg} / \mathrm{dm}^{3}$ & 0.769 & 0.774 & 0.775 & 0.762 \\
\hline$v_{40^{\circ} \mathrm{C}}$ & $\mathrm{mm}^{2} / \mathrm{s}$ & 1.88 & 2.03 & & - \\
\hline $\mathrm{DCN}$ & - & 83 & 79.6 & 76 & 75.5 \\
\hline Flash Point & ${ }^{\circ} \mathrm{C}$ & 77.7 & 80 & 78 & 79 \\
\hline $\mathrm{CP} / \mathrm{CFPP}$ & ${ }^{\circ} \mathrm{C}$ & $-9 /-13$ & $-56 /-58$ & $-16 /-18$ & $-20 /-22$ \\
\hline
\end{tabular}

Table 4. Physicochemical Properties of HPFT Diesel (IDW- Catalyst)

\begin{tabular}{|l|l|l|l|l|}
\hline \multicolumn{1}{|c|}{ Parameter } & \multicolumn{1}{c|}{ Unit } & \multicolumn{1}{c|}{ 64h } & \multicolumn{1}{c|}{$\mathbf{1 0 4 h}$} & \multicolumn{1}{c|}{$\mathbf{1 2 8 h}$} \\
\hline $\begin{array}{l}\text { Temp./ WHSV/ } \\
\text { Press. }\end{array}$ & ${ }^{\circ} \mathrm{C} / \mathrm{h}^{-1} / \mathrm{MPa}$ & $385 / 0.67 / 6$ & $390 / 0.67 / 6$ & $395 / 0.67 / 6$ \\
\hline Feed: & & \multicolumn{3}{|c|}{ FT-Biowax/ HGO=95/ 5 \% Vol } \\
\hline Boiling Range & ${ }^{\circ} \mathrm{C}$ & \multicolumn{3}{c|}{$175-380$} \\
\hline C- Number Range & - & \multicolumn{3}{c|}{$\mathrm{C} 10-\mathrm{C} 25$} \\
\hline i/n- Paraffins & $\%$ & $92.2 / 5.2$ & $91.8 / 5.5$ & $89.0 / 8.1$ \\
\hline Aromatics & $\%$ & 2.6 & 2.7 & 2.9 \\
\hline$\rho_{15^{\circ} \mathrm{C}}$ & $\mathrm{kg} / \mathrm{dm}^{3}$ & 0.784 & 0.783 & 0.784 \\
\hline$v_{40}{ }^{\circ} \mathrm{C}$ & $\mathrm{mm} / \mathrm{s}$ & 2.53 & 2.56 & 2.76 \\
\hline $\mathrm{CP} / \mathrm{CFPP}$ & ${ }^{\circ} \mathrm{C}$ & $-49.8 /-49$ & $-49.3 /-50$ & $-31.2 /-35$ \\
\hline
\end{tabular}

Table 5. Physicochemical Properties of HPFT- Kerosene (IDW- Catalyst)

\begin{tabular}{|c|c|c|c|c|}
\hline Parameter & Unit & $64 h$ & $104 h$ & $128 \mathrm{~h}$ \\
\hline $\begin{array}{l}\text { Temp./ WHSV/ } \\
\text { Press. }\end{array}$ & ${ }^{\circ} \mathrm{C} / \mathrm{h}^{-1} / \mathrm{MPa}$ & $385 / 0.67 / 6$ & $390 / 0.67 / 6$ & $395 / 0.67 / 6$ \\
\hline Feed: & & \multicolumn{3}{|c|}{ FT-Biowax/ HGO= 95/ $5 \%$ Vol } \\
\hline Boiling Range & ${ }^{\circ} \mathrm{C}$ & \multicolumn{3}{|c|}{$175-225$} \\
\hline C- Number Range & - & \multicolumn{3}{|c|}{$\mathrm{C} 10-\mathrm{C} 14$} \\
\hline i/n- Paraffins & $\%$ & $89.7 / 7.4$ & $89.3 / 7.9$ & $86.1 / 10.9$ \\
\hline Aromatics & $\%$ & 2.63 & 2.81 & 3.05 \\
\hline$\rho_{15^{\circ} \mathrm{C}}$ & $\mathrm{kg} / \mathrm{dm}^{3}$ & 0.758 & 0.757 & 0.756 \\
\hline$v_{40^{\circ} \mathrm{C}}$ & $\mathrm{mm}^{2} / \mathrm{s}$ & 1.20 & 1.22 & 1.22 \\
\hline$V_{-20^{\circ} \mathrm{C}}$ & $\mathrm{mm}^{2} / \mathrm{s}$ & 4.11 & 4.13 & 4.21 \\
\hline Freezing Point & ${ }^{\circ} \mathrm{C}$ & -77 & -76 & -71 \\
\hline
\end{tabular}




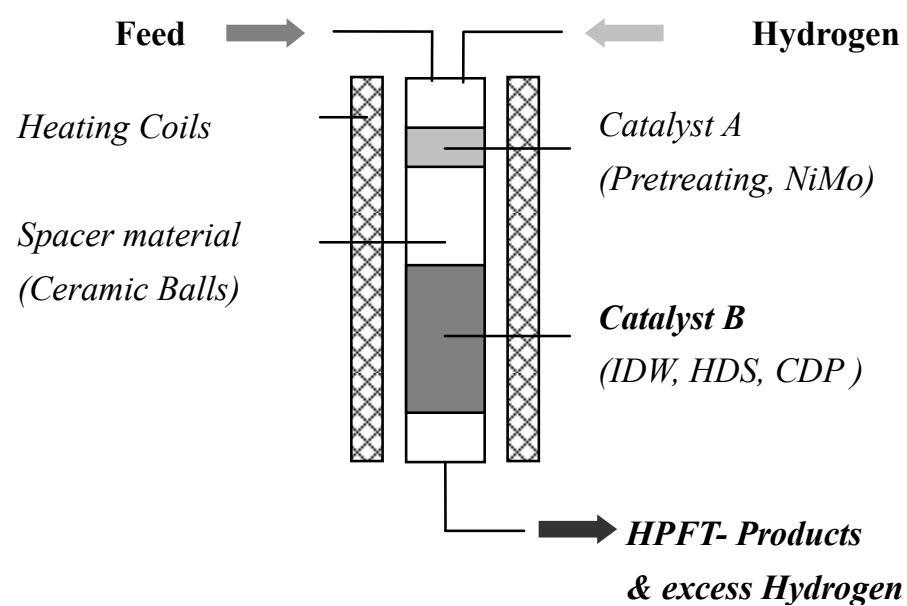

Figure 1. Schematic of pilot plant (OMV)

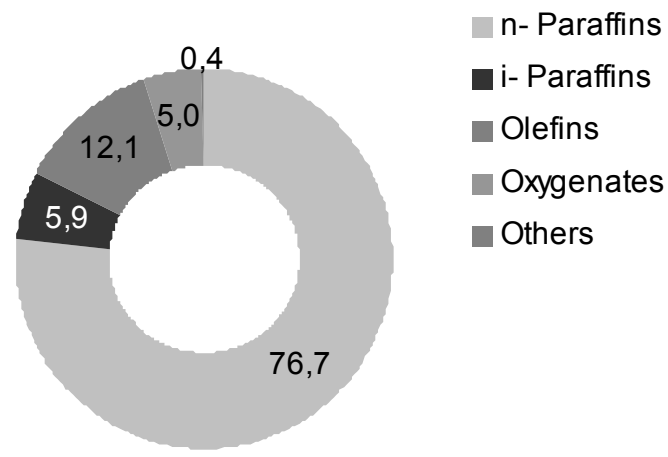

Figure 2. Composition of FT- Biowax (Guessing)

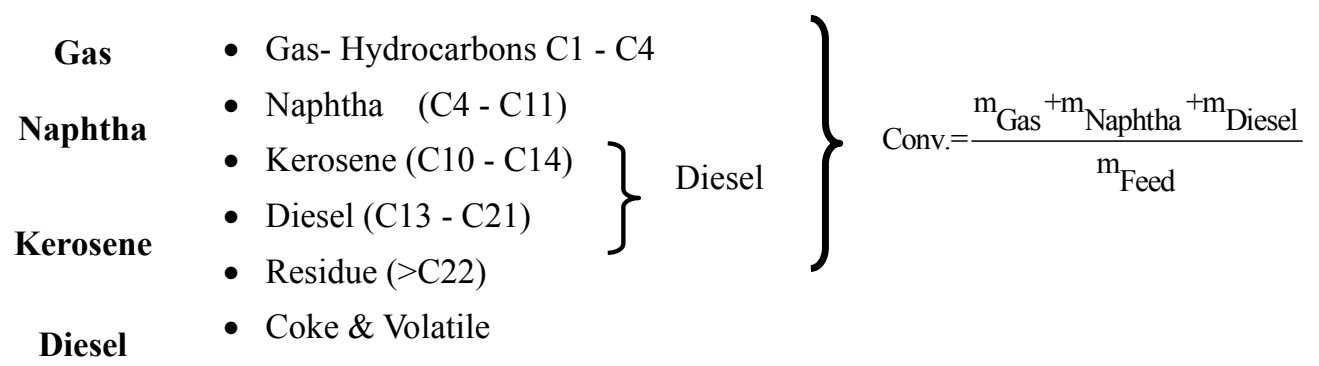

\section{Residue}

\section{Coke}

Figure 3. HPFT- Product Groups 


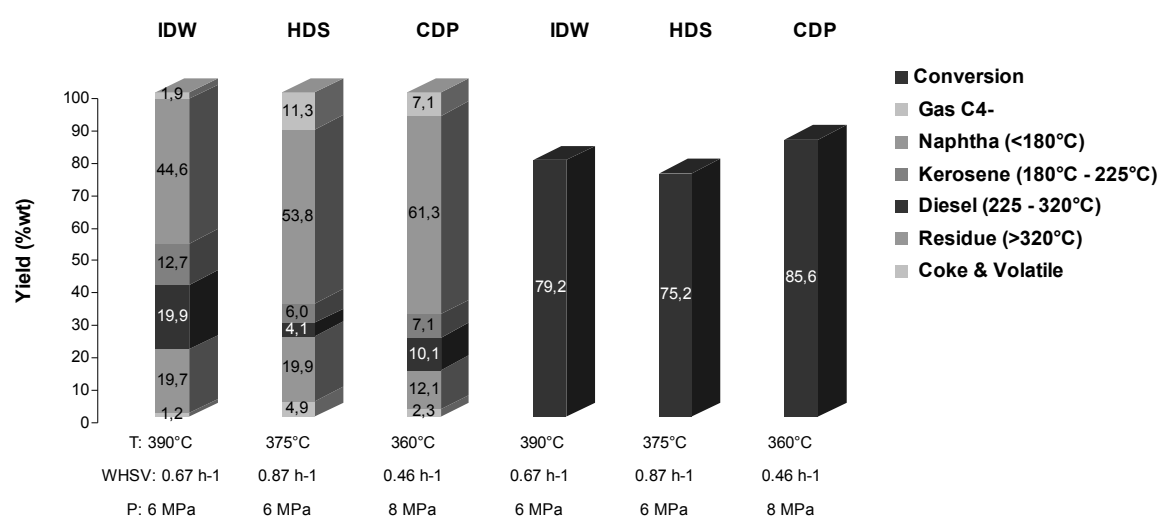

Figure 4. Product Yields and Conversion

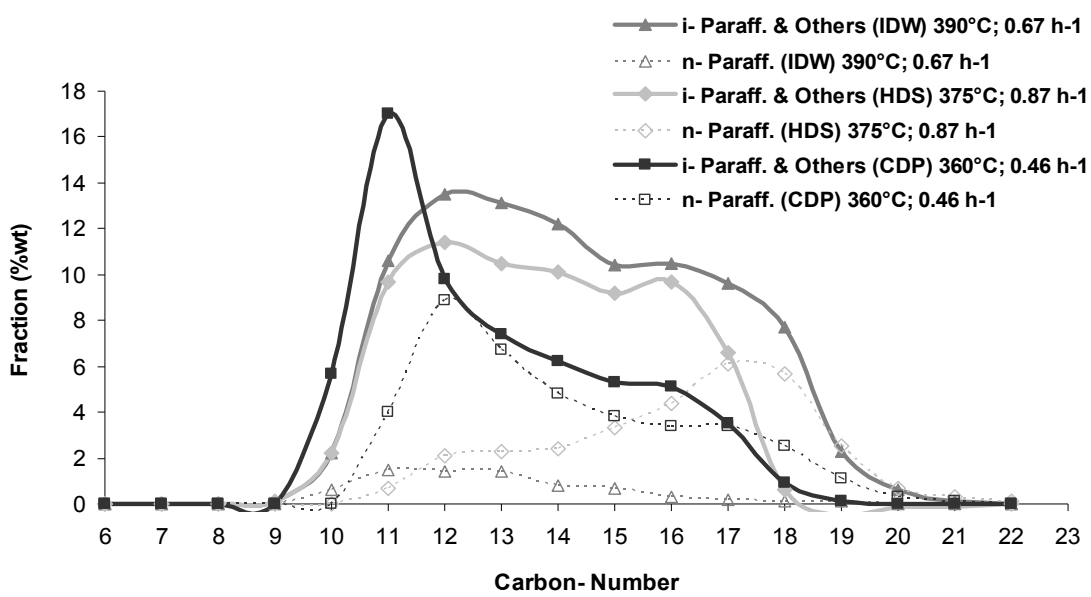

Figure 5. Profile of HPFT- Diesel (1d GC)

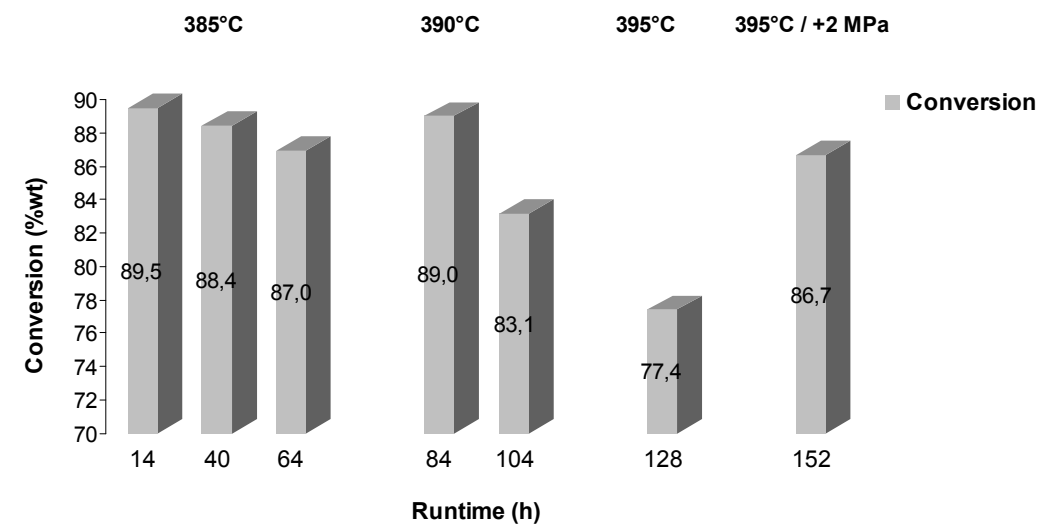

Figure 6. Conversion depending on runtime of IDW- Catalyst 


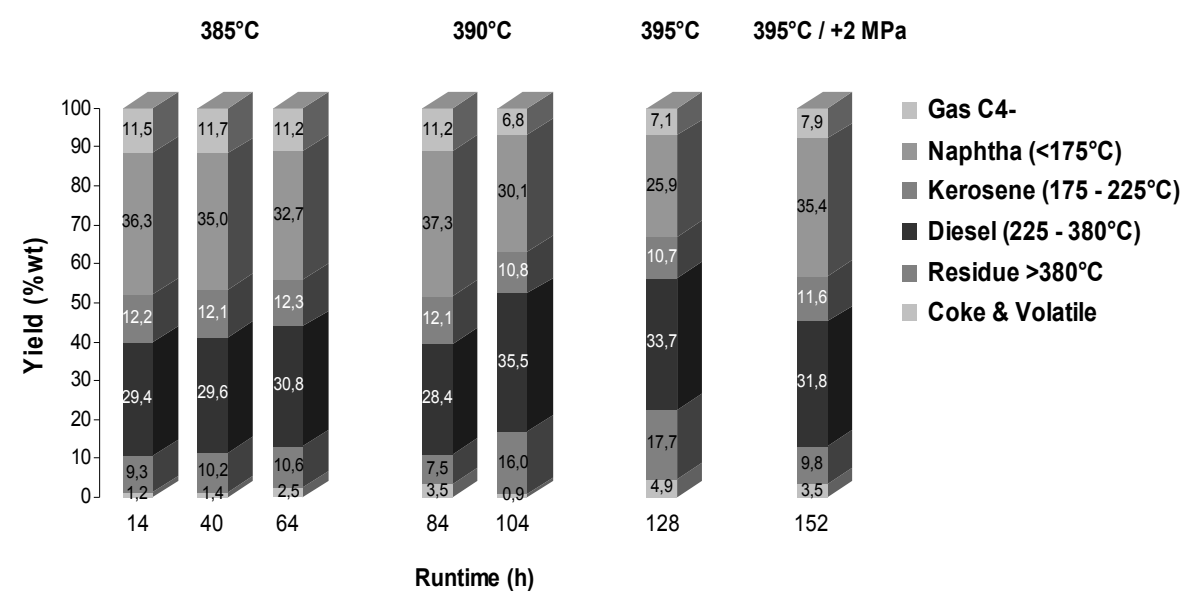

Figure 7. Yields depending on runtime of IDW- Catalyst

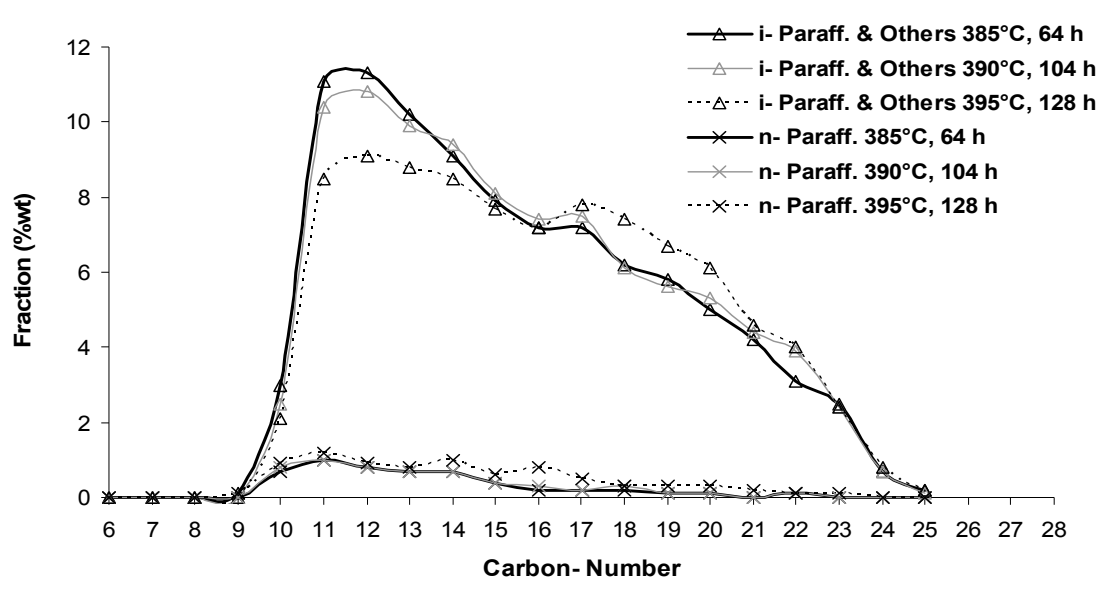

Figure 8. Profile of HPFT- Diesel (1d GC, IDW-Catalyst)

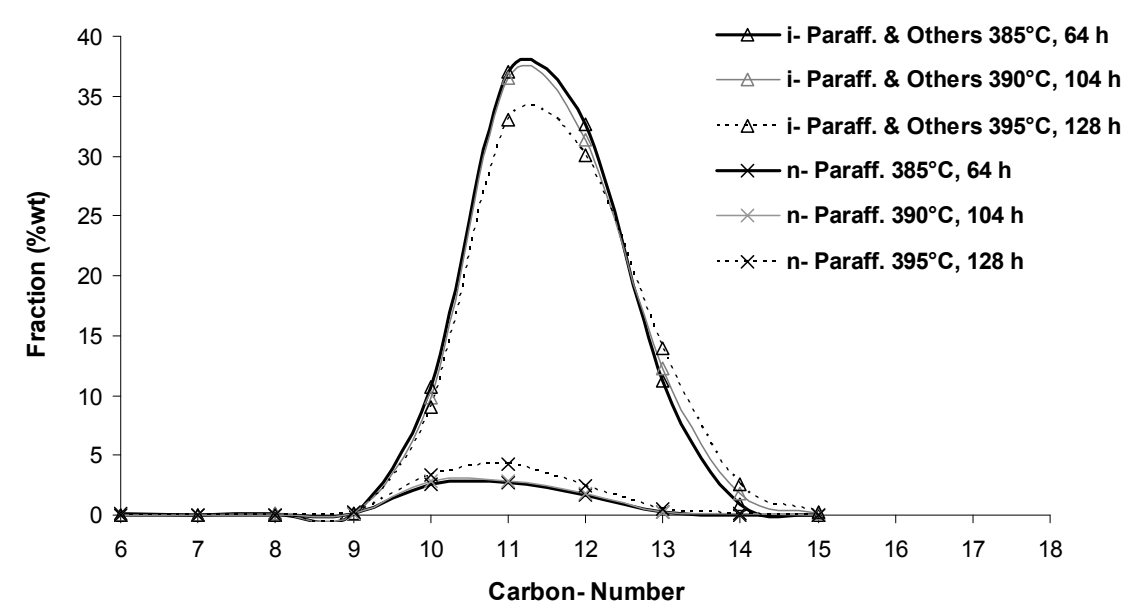

Figure 9. Profile of HPFT- Kerosene (1d GC, IDW- Catalyst) 